\title{
Article \\ Critical Success Factors for Safety Training in the Construction Industry
}

\author{
Algan Tezel ${ }^{1, *(\mathbb{D}}$, Esra Dobrucali ${ }^{2}{ }^{\mathbb{D}}$, Sevilay Demirkesen ${ }^{3}$ and Isik Ates Kiral ${ }^{4}$ \\ 1 Department of Architecture and 3D Design, University of Huddersfield, Huddersfield HD1 3DH, UK \\ 2 Department of Civil Engineering, Sakarya University, Sakarya 54050, Turkey; eeken@sakarya.edu.tr \\ 3 Department of Civil Engineering, Gebze Technical University, Gebze 41400, Turkey; demirkesen@gtu.edu.tr \\ 4 Department of Civil Engineering, Istinye University, Istanbul 34010, Turkey; isik.kiral@istinye.edu.tr \\ * Correspondence: a.tezel@hud.ac.uk
}

Citation: Tezel, A.; Dobrucali, E.; Demirkesen, S.; Kiral, I.A. Critical Success Factors for Safety Training in the Construction Industry. Buildings 2021, 11, 139. https://doi.org/ 10.3390/buildings11040139

Academic Editors: Paulo Santos and Tinghua Yi

Received: 8 February 2021

Accepted: 25 March 2021

Published: 30 March 2021

Publisher's Note: MDPI stays neutral with regard to jurisdictional claims in published maps and institutional affiliations.

Copyright: (C) 2021 by the authors Licensee MDPI, Basel, Switzerland. This article is an open access article distributed under the terms and conditions of the Creative Commons Attribution (CC BY) license (https:// creativecommons.org/licenses/by/ $4.0 /)$.

\begin{abstract}
Construction is a hazardous industry. The project-based nature and fragmentation in the industry lead to change and uncertainty requiring special expertise. To handle those, construction firms must develop strategies and action plans along with the experience gained from lessons learned. Among the risks, safety risks are of critical importance leading to accidents. Hence, firms need to strengthen their safety programs, review their strategies for safety management, and develop effective safety training sessions to protect their workers. This study focuses on the success factors promoting safety performance. In this respect, a questionnaire was designed and administered to the Engineering News-Record (ENR) 2020 Top 400 Contractors. The questionnaire data was utilized in conducting a factor analysis to group and name the factors considering the total variance. The analysis of the factors resulted in six-factor groups; namely, project and firm-related factors, demographic factors, practical factors, motivational factors, organizational factors, and humanrelated factors. Project and firm-related factors were found to be the most essential factor group in terms of promoting the effectiveness of safety training. The results of this study are expected to guide industry practitioners in terms of reviewing and revising their safety training programs.
\end{abstract}

Keywords: safety; construction; safety training; critical success factors

\section{Introduction}

The construction industry is one of the riskiest industries due to the high number of work-related hazards and injuries [1-5]. The U.S. Bureau of Labor Statistics (BLS) [6] reported that the total number of fatal work injuries in the U.S. was 5250, 1008 of which were in construction. Moreover, the total number of non-fatal work injuries was recorded as $2,834,500,199,100$ of which were in construction [6]. The work-related injuries and fatalities mostly stem from the fact that workers fail to comply with the rules in safety programs [7]. Heinrich's (1931) [8] study on safety indicated that a sequence of factors on worker mistakes combined with dangerous or unsafe behavior is the main cause of accidents. Bird and Germain (1990) [9] further mentioned that work accidents are preventable provided the underlying factors of accidents are well determined. Alarcón et al. (2016) [10] reported that the occurrence of work accidents is not random and due to several controllable factors. Durdyev et al. (2017) [11] mentioned that contractors might have taken early action towards promoting construction safety, if the factors affecting construction safety performance were studied. Similarly, Øien et al. (2011) [12] stated that studying the factors leading to accidents beforehand shall be effective in preventing major accidents. As a result, these studies raised a growing interest in construction safety (Guo et al., 2016) [13]. The study of factors leading to a high rate of injuries and fatalities in the construction industry revealed that inadequate training is one of the most important factors causing accidents [14]. To this end, Occupational Health and Safety Administration (OSHA) has various programs 
and initiatives towards creating a legal framework to regulate worker behavior and ensure work safety [15].

These programs focus on different attributes of safety management including safety training [16], which is an essential attribute of safety management [17]. It is possible to reduce the frequency of work-related injuries and fatalities with an effective safety training program [2]. Hence, it is critical to identify the underlying factors that make a safety program effective for the trainees and trainers. To identify those factors, observing the perception of workers on safety training is of the utmost importance [14]. Effective safety training results in better outcomes in the field in the context of safety management [3]. Rodríguez-Garzón et al. (2015) [18] suggested that training is an essential factor for improving safety climate, impacting safety perceptions, and changing safety behavior in construction projects. Recent studies also found that safety training can help to enhance the use of PPE among construction workers $[19,20]$. They further stated that training is essential to correct biased safety perceptions of construction workers and reinforce their safety knowledge such as motivating them to properly use personal protective equipment (PPE). Hasanzadeh et al. (2020) [21] emphasized that reducing human errors is possible through increasing the level of protective safeguards such as organizing safety training for workers, setting safety standards, and fostering the use of PPE. These have potential to avoid injuries resulting in a reduced total recordable injury rate. Reiman et al. (2017) [22] highlighted the essential role of safety training in developing different learning styles and affect individuals' behavior in safety. Man et al. (2019) [23] underline that safety training programs help increase workers' risk perception, resulting in minimized risktaking behavior. Hence, this study aims to reveal the factors contributing to the success of safety training sessions, which eventually lead to enhanced safety performance.

Even though previous studies assessed safety training methods for construction workers, the studies aiming to scrutinize the factors leading to a more effective safety training are scarce. To fill this gap in the literature, this study conducts an in-depth literature review regarding the factors affecting the performance of safety training and presents a comprehensive list of factors accordingly. Moreover, the study groups these factors to associate them with the categories of safety-related facts. The study is expected to assist construction practitioners in terms of creating a successful safety program by revealing the most critical factors to consider. The results of the study might also prompt researchers to focus more on safety training, which is an essential element of reducing work-related injuries and fatalities in the construction industry.

\section{Materials and Methods}

The majority of work-related accidents on construction sites stem from unsafe actions and conditions [24,25]. Both researchers and industry practitioners are seeking new methods against the high number of accidents in the construction industry [3]. There are various methods mentioned in the previous works to enhance the performance of safety practices. For example, Lai et al. (2011) [26] focused on human resource (HR) practices (recruitment, incentives and rewards, safety training, communication, and feedback, etc.). In their study, they pointed out the importance of establishing safety policies based on effective HR practices to improve safety management on construction sites. Hinze et al. (2013) [27] focused on key indicators to assess construction safety and proposed a simple formula for "percent of worker observations that were safe," and "the number of positive reinforcements provided per 200,000 h". A considerable portion of the studies developed models or present strategies for increased safety performance such as the safety culture interaction (SCI) model [28], plan-prevent-protect strategy [29], fatigue assessment scale for construction workers (FASCW) [30], and social-ecological model of safety performance improvement (SEM-SPI) [31].

Some studies investigated the factors affecting safety practices in the construction industry. These factors include but are not limited to:

- $\quad$ Management support 
- Fall protection systems

- Regular safety controls and effective communication

- Clear and acceptable objectives

- Teamwork

- Worker attitude

- Appropriate supervision and safety training

- Lack of training

- Poor safety awareness of management

- Unwillingness for safety and improper operations

- Site supervision and site condition

- Organizational and individual characteristics

- Management and organization, resources, site management and workforce

- Safety awareness, training and conducting safety control

- Social support and production pressure

- Work characteristics, knowledge, idiosyncratic perception of work and safety management

- Safety incentives and rewards

- Leadership, organizational commitment, management commitment, resource allocation and safety training

- Personal awareness and communication

- Work experience, type of accident, and unsafe behavior and conditions [10,11,13,16,17,32-39].

Being the main focus of this study, safety training holds an important place among the factors affecting safety performance. Several studies have already implied the critical role of the training in reducing the number of unsafe acts and behavior. For example, Sollis-Carcadio and Franco-Poot (2014) [40] found that workers who had limited safety training and developed a poor safety culture are more vulnerable to being involved in accidents. Moreover, workers who had proper safety training are more likely to identify hazards and develop a safety risk perception [41,42]. Tam and Fung (2012) [43] determined that compulsory training raises construction workers' interest in safety. Training designed following the needs of workers having different levels of knowledge yields a higher efficiency in terms of safety $[3,43]$. Hence, workers who received safety training were critical to the development of safety programs and management [14]. Ho and Dzeng (2010) [44] proved that a suitable safety training has the potential to promote safe behavior. Kaskutas et al. (2013) [45] concluded that foremen who had completed safety training developed more effective safety communication practices. A significant portion of previous studies shows that incorporating technology and specifically virtual reality (VR) in a safety training session is an effective means of enhancing the efficiency and quality of the training [46-52]. VR is effective in attracting trainees' attention and strengthening learning in construction safety training [46].

Previous studies also focused on the impact of safety training on immigrant construction workers [53-55]. Williams et al. (2010) [53] revealed that immigrant workers are willing to improve their knowledge of safety. The study also found that the number of hazardous behaviors among immigrant workers had reduced after an effective safety training session. Furthermore, Han et al. (2008) [54] stated that training is essential for a better communication with immigrant construction workers. O'Connor et al.'s (2005) [55] study showed that immigrant workers are generally less trained in terms of safety compared to other workers on the site.

Learning constitutes an important part of an effective safety training [3]. However, workers might fail to practice what they learned from the training when they returned to work $[5,56]$. Therefore, several studies highlighted the critical role of transfer of training, concluding that the involvement of stakeholders positively affects the training transfer $[57,58]$.

Given this general background, this study focuses on determining the critical success factors (CSF) of an effective safety training program. In this context, both qualitative and 
quantitative methods were adopted. As part of the qualitative methods, a content analysis and an in-depth literature review were conducted. Moreover, expert interviews were conducted to create a consensus for the identification of the safety training variables. Then, a survey study with factor analysis was employed. The survey helped assess and quantify the variables identified. Moreover, statistical data was analyzed based on the responses collected. The survey also revealed information regarding the position, background, and experience of the respondents. The factor analysis was conducted to group the variables in a coherent factor and name as a categorical group. The scarcity of resources investigating the variables making a safety training program effective and the gap in the literature are the main motivations for the study. The study assesses these critical factors with a careful consideration of the recent research in this domain, revealing the need for such research in the construction industry. Table 1 presents the safety training success variables adopted for this study based on an in-depth analysis of the previous studies.

Table 1. Safety training success variables.

\begin{tabular}{|c|c|c|}
\hline Variable & Explanation & References \\
\hline Age & $\begin{array}{l}\text { Age is listed as an essential parameter in terms of affecting the } \\
\text { success of safety training for the fact that there may be a significant } \\
\text { difference in the safety training perceptions of younger and older } \\
\text { workers. }\end{array}$ & {$[14,36,42,44,53,55,59-61]$} \\
\hline Gender & $\begin{array}{l}\text { Gender is indicated as an important parameter in the success of } \\
\text { safety training since differences might be observed in safety } \\
\text { training success depending on workers' genders. }\end{array}$ & {$[5,14,44,59,61]$} \\
\hline Country of Origin & $\begin{array}{l}\text { Country of origin is another essential factor affecting the success of } \\
\text { training sessions since people from different origins might develop } \\
\text { different perceptions of safety. }\end{array}$ & {$[14,53,55,59]$} \\
\hline Educational Background & $\begin{array}{l}\text { The level of education might be a strong indicator of safe behaviors. } \\
\text { Hence, educational background is listed as an important parameter } \\
\text { for safety training success. }\end{array}$ & {$[14,36,44,53,58,61]$} \\
\hline Language & $\begin{array}{l}\text { There is strong evidence that language might become a barrier in } \\
\text { safety training sessions. Thus, language is considered as an } \\
\text { important component of safety training success. }\end{array}$ & {$[3,14,26,55,62,63]$} \\
\hline Work Experience & $\begin{array}{l}\text { Work experience is a directly related parameter with safety training } \\
\text { since experienced workers are more likely to promote safety } \\
\text { training success. }\end{array}$ & {$[14,36,53,55,59,62]$} \\
\hline $\begin{array}{c}\text { Perception of Safety } \\
\text { Training }\end{array}$ & $\begin{array}{l}\text { Perception of safety training is critical in terms of putting the } \\
\text { training into practice. A strong/positive perception of safety } \\
\text { training leads to a successful implementation of what was learned } \\
\text { in a safety training session. }\end{array}$ & {$[3,5,43,46]$} \\
\hline Hands-on Training & $\begin{array}{l}\text { Hands-on training is an effective practice in terms of promoting } \\
\text { safety training since it is linked with real cases on construction sites } \\
\text { leading to a better training session considering worker needs. }\end{array}$ & {$[3,5,43,46,58,64]$} \\
\hline Training Frequency & $\begin{array}{l}\text { Training frequency is important for the success of safety training } \\
\text { sessions. More frequent training results in better reinforced } \\
\text { learning of safety. }\end{array}$ & {$[5,43,44,61,65,66]$} \\
\hline Methods and Materials & $\begin{array}{l}\text { Methods and materials used in safety training sessions are of } \\
\text { utmost importance in terms of promoting safety. They help } \\
\text { elucidate essential safety information for workers through learning, } \\
\text { strategies, and equipment. }\end{array}$ & {$[3,5,14,43,63,64,66,67]$} \\
\hline Training Satisfaction & $\begin{array}{l}\text { Training satisfaction is directly related to safety training as the level } \\
\text { of satisfaction, comprehension, and emotional engagement in } \\
\text { training contributes to the success of safety training sessions. }\end{array}$ & {$[20,44,61]$} \\
\hline
\end{tabular}


Table 1. Cont.

\begin{tabular}{|c|c|c|}
\hline Variable & Explanation & References \\
\hline $\begin{array}{l}\text { Safety Awareness and } \\
\text { Motivation }\end{array}$ & $\begin{array}{l}\text { Safety awareness and motivation are crucial for the success of } \\
\text { safety training. This is simply described as the level of knowledge } \\
\text { concerning unsafe acts or behaviors and the need for motivation for } \\
\text { safe practices. }\end{array}$ & {$[3,38,46,58,64,65,68]$} \\
\hline $\begin{array}{l}\text { Number of Unsafe Acts } \\
\text { and Accidents }\end{array}$ & $\begin{array}{l}\text { Developing a prior knowledge of unsafe acts and accidents } \\
\text { constitutes an important part of safety training success. Hence, the } \\
\text { number of unsafe acts and incidents affects the effectiveness of } \\
\text { safety training sessions. }\end{array}$ & {$[44,46,61]$} \\
\hline Effectiveness of Training & $\begin{array}{l}\text { The success of safety training depends on the effectiveness of } \\
\text { training. Effectiveness represents the developed understating of the } \\
\text { severity and consequences of safety-related accidents after } \\
\text { the training. }\end{array}$ & {$[14,36,44,46,53,62]$} \\
\hline $\begin{array}{l}\text { Coordination and } \\
\text { Collaboration }\end{array}$ & $\begin{array}{l}\text { Coordination and collaboration in safety training sessions lead to } \\
\text { information sharing and observational environment among } \\
\text { trainees. This eventually contributes to the success of } \\
\text { safety training. }\end{array}$ & {$[3,44,46,50,64]$} \\
\hline Feedback & $\begin{array}{l}\text { Feedback is an essential part of safety training sessions. Providing } \\
\text { feedback after a training session, especially regarding the trainee } \\
\text { performance, leads to a higher success in the training. }\end{array}$ & {$[3,51,58,64]$} \\
\hline Management Support & $\begin{array}{l}\text { Effective training is only possible with strong management support. } \\
\text { This contributes to higher performance in the training sessions. }\end{array}$ & {$[3,58,64]$} \\
\hline $\begin{array}{l}\text { Use of Personal } \\
\text { Protective Equipment } \\
\text { (PPE) }\end{array}$ & $\begin{array}{l}\text { One of the most important subjects in safety is to promote the use } \\
\text { of PPEs through safety training sessions. Providing workers with a } \\
\text { core training section of the PPE use is strongly related to safety } \\
\text { training success. }\end{array}$ & {$[38,43,46,48,49,55,58,63,66,69]$} \\
\hline Firm Size & $\begin{array}{l}\text { Firm size is associated with the scope and content of safety training } \\
\text { considering the budget and resources spared for the training } \\
\text { sessions. This in turn affects the success of training sessions. }\end{array}$ & {$[3,5,48,59,60,66]$} \\
\hline Project Type & $\begin{array}{l}\text { Safety training sessions differ depending on project type. Hence, it } \\
\text { is important to design safety training content by the different } \\
\text { requirements of project types }\end{array}$ & {$[42,44,48,55]$} \\
\hline Project Duration & $\begin{array}{l}\text { Project duration determines the ability to design training sessions } \\
\text { in varying durations and content. This directly affects the success of } \\
\text { safety training. }\end{array}$ & {$[44,52]$} \\
\hline Leadership & $\begin{array}{l}\text { Leadership is effective in terms of promoting safer practices. } \\
\text { Exemplary leadership has a positive impact on the success of safety } \\
\text { training sessions. }\end{array}$ & {$[13,15,33,37,38]$} \\
\hline Project size & $\begin{array}{l}\text { Project size refers to the scale of projects in regards to budget and } \\
\text { workload. Project size shapes the content and duration of safety } \\
\text { training, which in turn affects the success of training sessions. }\end{array}$ & {$[26,31,42,70]$} \\
\hline Incentives for Safety & $\begin{array}{l}\text { Incentives for safety have the potential to promote safety training } \\
\text { sessions and safe behaviors through positive reinforcement. }\end{array}$ & {$[26,37,38,64,65,70]$} \\
\hline Training Language & $\begin{array}{l}\text { Training language is directly related to the success of safety training } \\
\text { sessions since some trainees fail to practice what they learned in } \\
\text { training sessions when the training language is not their } \\
\text { mother tongue. }\end{array}$ & {$[3,55,58,66,71]$} \\
\hline
\end{tabular}

\section{Research Methodology}

This study explores the CSFs in safety training sessions in the construction industry. To determine these factors and cluster them in a coherent scheme, an online survey was designed and administered to the construction firms listed in the Engineering News-Record (ENR)'s 2019 Top Contractors List. According to the data on the ENR website, the firms 
listed in the Top 400 Contractors in 2018 generated a revenue of US $\$ 405$ billion in 2018, where this was US $\$ 373.98$ billion in 2017 [72]. This indicates that these firms on the list generate most of the construction value and shows their extensive presence in the industry. The survey consists of two sections, namely the general information about the respondents and the success factors in safety training. The survey designed is presented in Appendix A. The first sections aimed at collecting data regarding the characteristics of the respondents such as respondent age, total turnover, number of employees, educational background, and years of operation in the construction industry. The second part consists of questions about the success factors in safety training sessions. In the second part, a 5-point Likert Scale was adopted to rate the success factors, where 1 represents very low and 5 represents very high. A total of 400 surveys were sent out and 93 responses were collected at a response rate of $23 \%$. The survey data was analyzed using the Factor Analysis tool of SPSS 23. The factor analysis was utilized to identify which underlying factors are measured by a considerably larger number of observed variables. The analysis of the data collected through the survey is provided in the following sections.

\subsection{General Information about the Respondents}

The respondent characteristics were sought to better interpret the results. Table 2 presents the respondents' characteristics such as the age of the firm, annual turnover, and the number of employees. According to Table 2, the average firm age is 45 , whereas the maximum and minimum ages are 69 and 27, respectively. The annual turnover of the responding firms was reported as US\$181.81 million on average, where the maximum turnover is US\$806 million, and the minimum is US\$1 million. Finally, the total number of employees was reported as 876 on average, where the maximum number is 3700 and the minimum is 58 .

Table 2. Respondent Characteristics.

\begin{tabular}{ccccc}
\hline Characteristic & Maximum & Minimum & Average & Median \\
\hline Age of the Firm (Years) & 69 & 27 & 45 & 45 \\
Annual Turnover (in Million US\$) & 806.00 & 1.00 & 181.81 & 113.00 \\
Number of Employees & 3700 & 58 & 876 & 847 \\
\hline
\end{tabular}

The first part of the survey also collected information regarding the respondent's gender, origin, and educational level. Figure 1 presents data regarding the gender of the respondents. According to Figure 1, $82 \%$ of the respondents are male, whereas $18 \%$ of the respondents are female. Figure 2 presents the origin of the respondents. According to Figure 2, the majority of the respondents' origin is United States (81.7\%) and the remaining origins are from other countries.

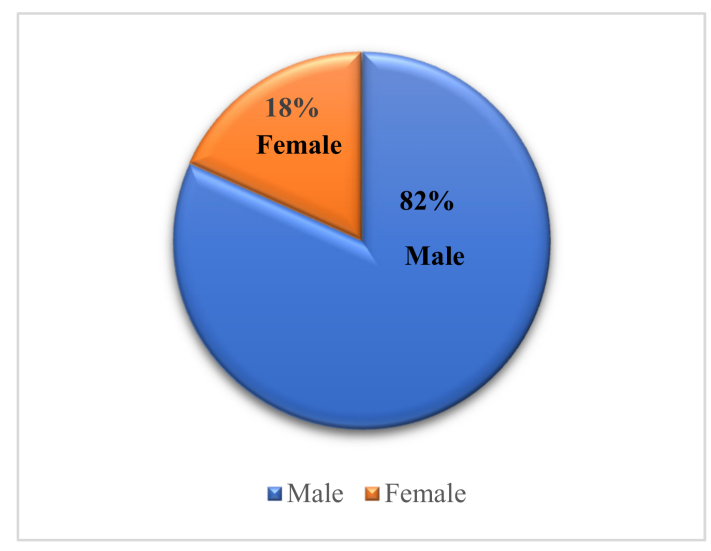

Figure 1. Respondents' gender. 


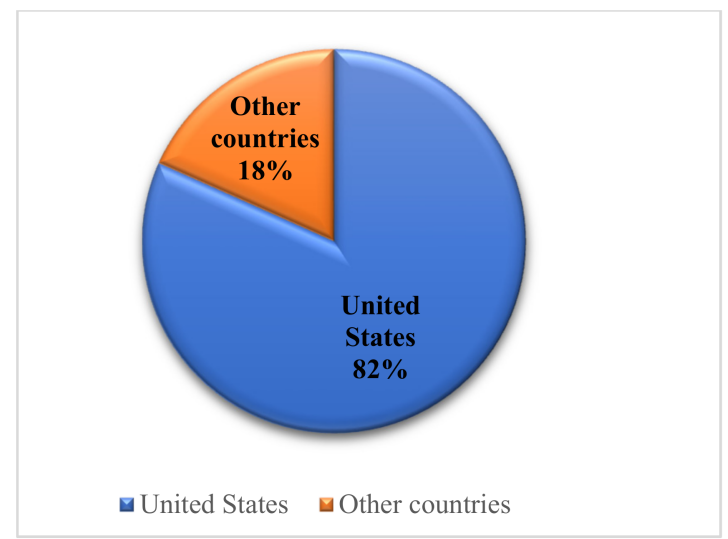

Figure 2. Origin of the respondents.

Figure 3 exhibits the level of education of the respondents, where $63 \%$ of the respondents hold an MSc. degree, and 29.0\% BSc., 6.5\% Ph.D., and 1.5\% of the respondents are high school graduates, respectively. Figure 4 presents the respondents' current role in the construction industry. According to this, $39.8 \%$ of the respondents are project managers, $23.7 \%$ are engineers, $12.9 \%$ are general managers, and $23.6 \%$ have other roles such as foreman, safety directors, safety supervisors, and architects. The analysis of both figures revealed that the majority of the respondents hold an MSc degree and work at the project manager position.

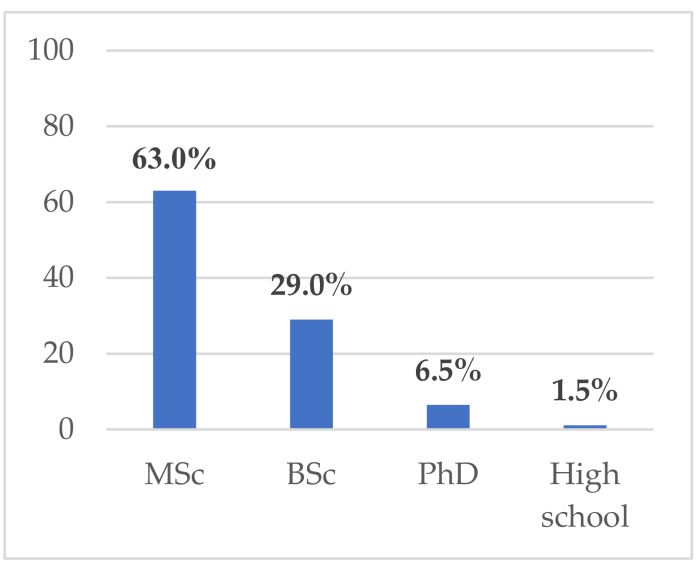

Figure 3. Education level of the respondents.

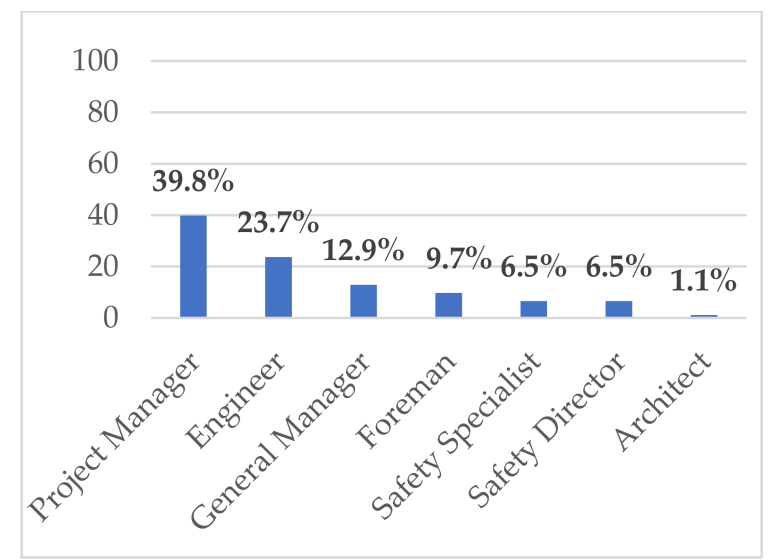

Figure 4. Respondents' current role in the construction industry. 
Figure 5 shows the years of operation of the responding firms in the construction industry. According to this, $37.6 \%$ of the firms have been operating in the construction industry for more than 20 years, where $30.1 \%$ have been operating in the industry between $15-20$ years, $22.6 \%$ have been operating in the industry between $10-15$ years, $8.6 \%$ have been operating in the industry between 5-10 years, and $1.1 \%$ of the firms reported the years of operation less than 5 years. The respondents were further categorized according to their years of experience in the construction industry as shown in Figure 6. The majority of the respondents $(33.3 \%)$ have been working in the construction industry for 15-20 years. Twenty-nine percent of the respondents reported an experience interval of $10-15$ years. A considerable percentage of the respondents (17.2\%) reported that they have more than 20 years of experience in the construction industry. The remaining respondents reported 5-10 years of experience (10.8\%) and less than 5 years of experience $(9.7 \%)$ in the construction industry. The analysis of both figures indicated that the majority of the firms are quite experienced in the construction industry and a major portion of the respondents have much experience in the industry.

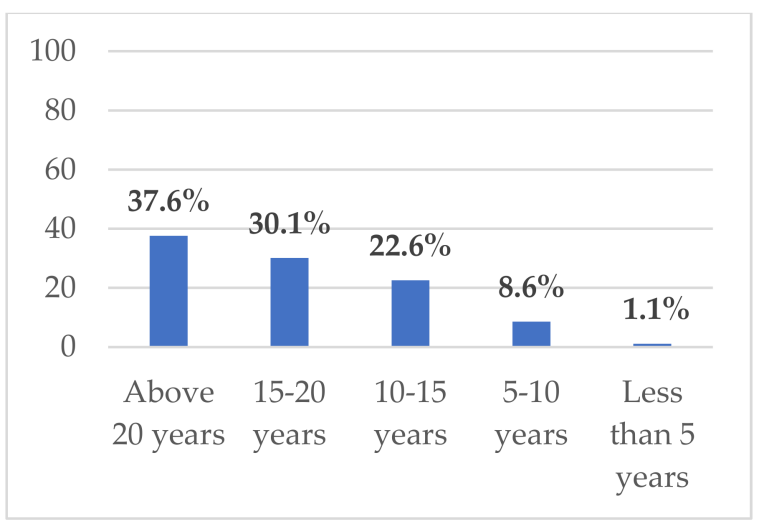

Figure 5. Years of operation in the construction industry.

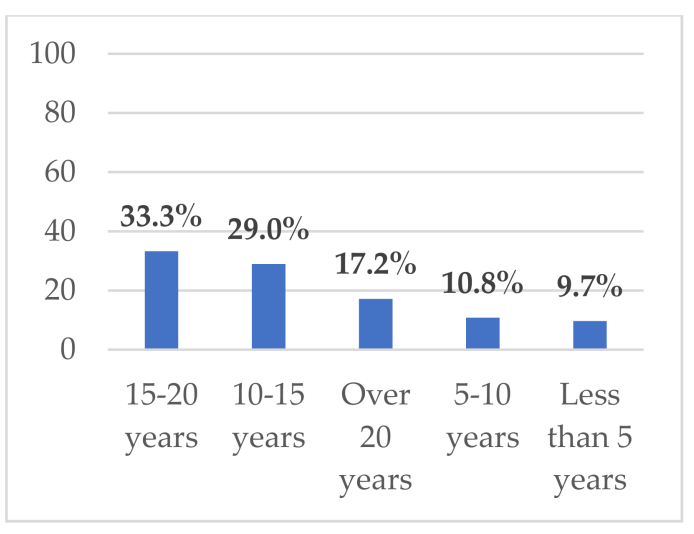

Figure 6. Respondents' years of experience in the construction industry.

In the survey, the respondents were asked whether there were previously involved in a safety training session. All respondents indicated they have previously participated in a safety training session. Moreover, the number of safety training attended by the respondents was assessed. According to the data collected, 52.7\% of the respondents have previously participated in safety training sessions one to three times, $36.6 \%$ of the respondents reported three to five times, and $10.8 \%$ indicated that they had been involved in a safety training session more than five times.

The survey also collected the satisfaction level of the respondents regarding the previous safety training that they had. Figure 7 presents the satisfaction level reported by the respondents. According to this, a major portion $(90.3 \%)$ of the respondents implied that 
their satisfaction was high with the previous training they had. Of the respondents, $4.3 \%$ indicated that they had very high satisfaction with the previous training, whereas $5.4 \%$ reported that they had a medium satisfaction level with the training they had received.

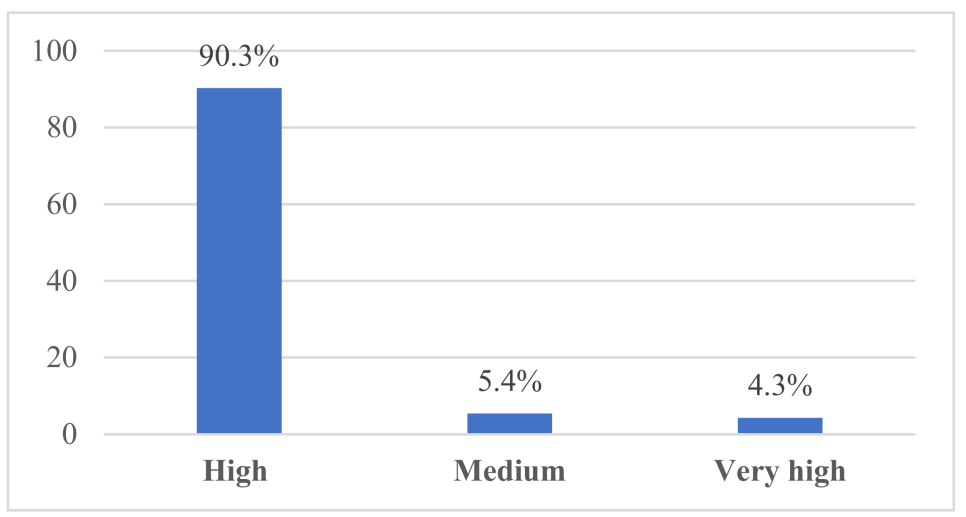

Figure 7. Respondents' satisfaction level with previous training.

The respondents responded to the main causes of unsafe behaviors or acts such as low perception of safety, inattention, and improper use of personal protective equipment (PPE). The respondents emphasized that effective safety training helped them avoid unsafe behaviors and increased their ability to detect unsafe conditions. Moreover, the respondents were asked to report whether they had been involved in a work-related accident. The analysis of the results indicated that $35.5 \%$ of the respondents had already been involved in a work-related accident, whereas $64.5 \%$ reported they had not been involved in a workrelated accident before. The respondents who reported that they had been involved in a work-related accident, also stated that safety training helped them detect mistakes and avoid unsafe behavior to a great extent.

The survey further assessed the increase in safety awareness after safety training. Figure 8 presents that the safety awareness increased by $51-70 \%$ after having at least one safety training session for the majority of the respondents (57\%). Of the respondents, $35.5 \%$ indicated that the safety awareness increased by more than $71 \%$ after participating in a safety training session; $7.5 \%$ reported an increase between $31-50 \%$ in safety awareness as a result of a completed safety training session.

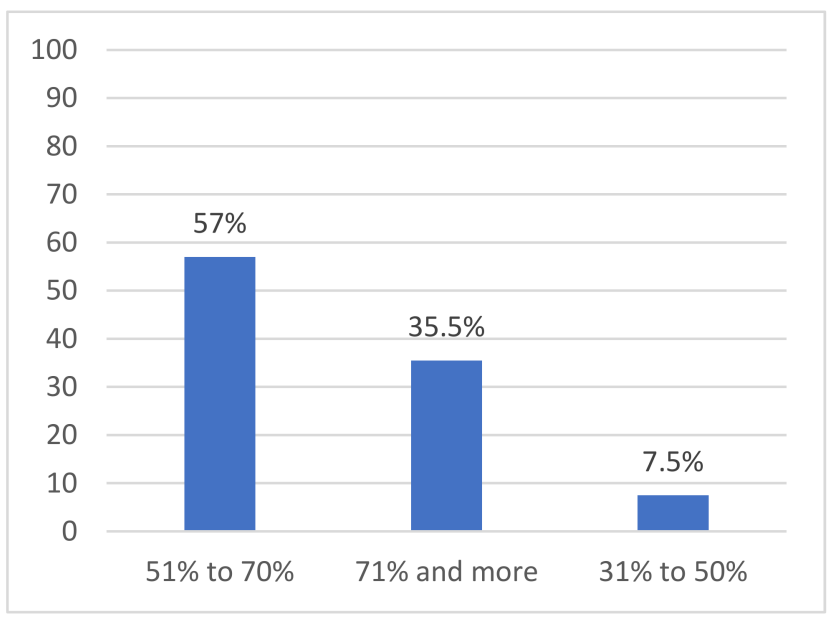

Figure 8. Increase in safety awareness rate after safety training.

The survey raised questions to the respondents regarding whether realistic examples from construction sites were provided in their safety training sessions. Of the respondents, $98.9 \%$ responded that realistic examples were included in the safety training sessions, 
whereas $1.1 \%$ reported that non-realistic examples were provided in the training sessions. Another question in the survey aimed to reveal whether the respondents had had any language problems in the safety training sessions. The analysis of the data showed that $11.8 \%$ of the respondents had problems in understanding the language of the safety training, where $88.2 \%$ reported that they did not have such a problem. Moreover, the respondents were asked to indicate whether they needed motivation to eliminate unsafe behavior. All respondents reported the need for motivation to eliminate unsafe behavior.

The survey further assessed the safety training methods utilized in the training sessions (Figure 9). All respondents reported that more than one training method was utilized in the training sessions. Accordingly, computer-based training $(94.6 \%)$ and on-the-job training $(91.4 \%)$ are the most commonly used methods in the training sessions.

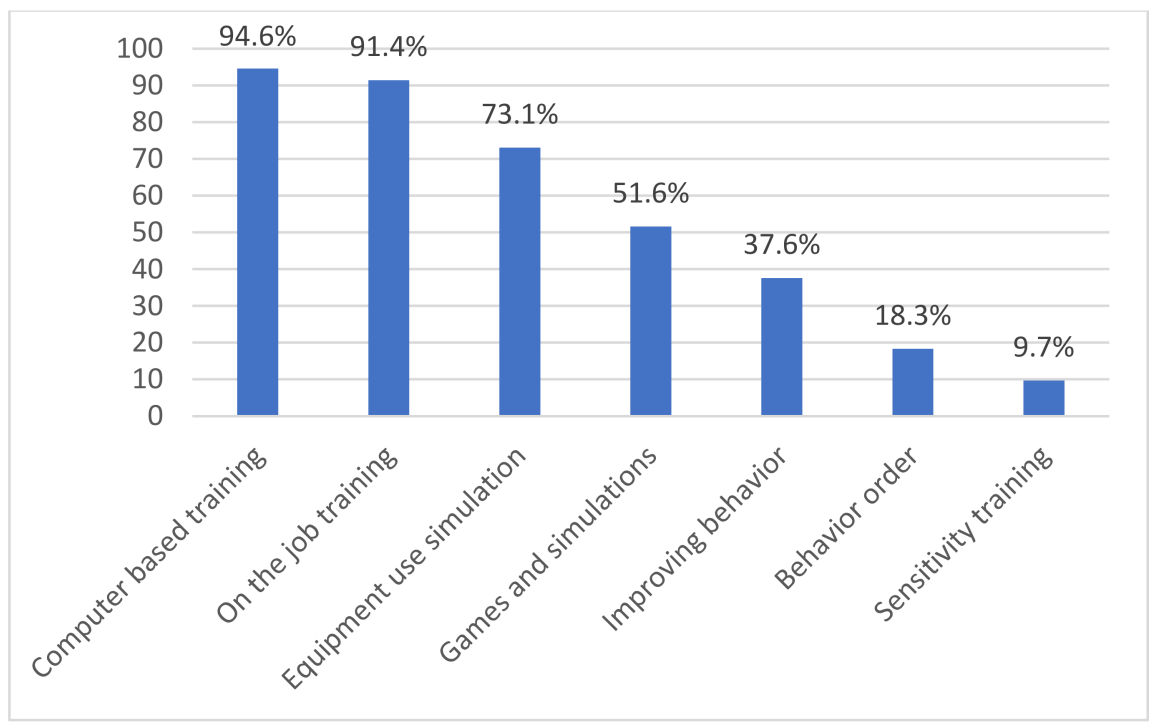

Figure 9. Safety training methods used in safety training sessions.

\subsection{Success Factors in Safety Training Sessions}

Safety training is challenging for several reasons such as content and audience issues. Considering the impact of safety training in increasing safety performance, more emphasis needs to be put on improving safety training effectiveness. This requires a critical analysis of the underlying factors for successful safety training sessions. Within this context, this study identifies a set of critical success factors (CSFs) for successful implementation of safety training. The CSFs of safety training sessions were identified through an in-depth analysis of the previous studies and interviews with the safety directors and managers. The interviews were conducted with safety directors and safety managers. The stratified sampling was used to identify the interviewees. A total of eight experts were selected for the interviews, where five of them are safety managers and three are safety directors. The inclusion criteria were to have experience with at least three safety training programmes in a project and a minimum of 5 years of experience in construction safety. Each interview was allotted $30 \mathrm{~min}$ and was conducted online. The interviews with the experts revealed the need for improvement regarding the training sessions so that trainees better learn and conceive the content and implement what they learned in the construction sites. In the initial step, a total of 41 variables were identified such as reward mechanisms for safety, training content, and training tools and techniques. After reviewing these 41 factors with industry experts and academics, some of the variables were merged into one variable, or some were removed to represent a coherent list of variables. For example, reward mechanisms and promotions were merged into one single variable as safety incentives. Moreover, communication was synthesized with coordination and collaboration variable. A similar approach was followed for the remaining variables. A final list composed of 25 safety training variables was produced after carefully revising the list (Table 3). 
Table 3. Descriptive Statistics of Safety Training Variables.

\begin{tabular}{|c|c|c|c|c|c|}
\hline Code & Variable & Mean & Std. Deviation & $\begin{array}{c}\text { Std. Deviation/Mean } \\
\text { (CV) }\end{array}$ & Variance \\
\hline V18 & $\begin{array}{c}\text { Use of Personnel Protective } \\
\text { Equipment }\end{array}$ & 4.95 & 0.23 & 0.05 & 0.05 \\
\hline V19 & Leadership & 4.92 & 0.27 & 0.05 & 0.07 \\
\hline V12 & $\begin{array}{c}\text { Safety Awareness and } \\
\text { Motivation }\end{array}$ & 4.91 & 0.32 & 0.07 & 0.10 \\
\hline V10 & Methods and Materials & 4.90 & 0.30 & 0.06 & 0.09 \\
\hline V11 & Training Satisfaction & 4.86 & 0.38 & 0.08 & 0.14 \\
\hline V14 & Effectiveness of Training & 4.83 & 0.38 & 0.08 & 0.14 \\
\hline V15 & $\begin{array}{l}\text { Coordination and } \\
\text { Collaboration }\end{array}$ & 4.74 & 0.46 & 0.10 & 0.22 \\
\hline V17 & Management Support & 4.71 & 0.48 & 0.10 & 0.23 \\
\hline V8 & Hands-on Training & 4.69 & 0.49 & 0.10 & 0.24 \\
\hline V24 & Incentives for Safety & 4.65 & 0.58 & 0.12 & 0.34 \\
\hline V16 & Feedback & 4.65 & 0.50 & 0.11 & 0.25 \\
\hline V13 & $\begin{array}{c}\text { Number of Unsafe Acts and } \\
\text { Accidents }\end{array}$ & 4.62 & 0.59 & 0.13 & 0.35 \\
\hline V25 & Training Language & 4.61 & 0.63 & 0.14 & 0.39 \\
\hline V7 & Perception of Training & 4.60 & 0.51 & 0.11 & 0.26 \\
\hline V9 & Training Frequency & 4.54 & 0.64 & 0.14 & 0.40 \\
\hline V6 & Work Experience & 4.41 & 0.63 & 0.14 & 0.40 \\
\hline V4 & Educational Background & 3.77 & 0.72 & 0.19 & 0.53 \\
\hline V5 & Language & 3.68 & 0.85 & 0.23 & 0.72 \\
\hline V20 & Project Type & 3.59 & 0.98 & 0.27 & 0.96 \\
\hline V22 & Project Duration & 3.58 & 1.01 & 0.28 & 1.03 \\
\hline V21 & Project Size & 3.58 & 1.00 & 0.28 & 1.01 \\
\hline V23 & Firm Size & 3.54 & 1.02 & 0.29 & 1.03 \\
\hline V2 & Gender & 3.37 & 1.00 & 0.30 & 1.00 \\
\hline V3 & Country of Origin & 3.35 & 0.96 & 0.29 & 0.93 \\
\hline V1 & Age & 3.32 & 0.98 & 0.30 & 0.96 \\
\hline
\end{tabular}

\section{Results}

Table 3 presents descriptive statistics for the CSFs based on the 93 responses collected. The results indicate that the use of PPE, leadership, safety awareness, and motivation are the most important success drivers in safety training sessions, whereas demographic variables such as age, country of origin, and gender are less important in terms of impacting the success of safety training sessions. A further investigation of the descriptive statistics indicated that the coefficient of variation (CV) for the variables lies between $0.05-0.30$, representing a significant variability and dispersion in the data set.

In the second phase, the factor analysis method was carried out to determine the underlying factors for safety training success. Factor analysis is a multivariate statistical method to reveal the correlated variables along with some independent factors, which represent a combination of the original variables [73-75]. The factor analysis helps group the variables into a meaningful and considerably smaller number of factors, which is also called factor extraction, by representing the relations among a set of interrelated variables. Factor analysis has two types, namely the exploratory factor analysis (EFA) and confirmatory factor analysis (CFA). EFA is carried out by identifying a set of factors maximizing the amount of variance required. CFA rather considers the factors based on an a priori hypothesis, which is an indication of the evaluation of the factors being mostly driven by the theory. This study adopts the EFA to identify the factors for safety training success. In this respect, the suitability of the data was assessed first by conducting the Kaiser-Meyer-Olkin (KMO) and Barlett's tests for sphericity. The KMO test presents the sampling adequacy with values lying between $0-1$, indicating the extent of prediction of one variable by other variables without error. Higher values of the test prove that the factor analysis is likely to produce more reliable and distinct factors. According to the 
scale defined by [70], KMO test values that are greater than 0.5 are acceptable, whereas the values between $0.5-0.7$ are mediocre, and the values between $0.7-0.8$ are considered to be good [76]. Bartlett's test checks whether the correlation matrix is an identity matrix [77].

The results of the KMO statistic were found to be 0.818 in this study. This value proves that the dataset is suitable for the factor analysis. The Barlett's test generated a Chi-square value of 2533.228 and the level of significance was found to be small $(p<0.0005)$ [78]. These values indicate that the factor analysis is an appropriate method for the dataset. The factor analysis was conducted using the SPSS 23 software. The analysis generated several files such as correlation matrix, total variance, component matrix, rotated component matrix, and the component plot in rotated space. The determinant value for the correlation matrix helps assess the singularity effect. It is considered that there is no singularity effect for the determinant values greater than 0.00001 [79]. The analysis of the data generated a determinant value of $5.22 \times 10^{-3}$, which is greater than 0.00001 , proving that there is no singularity effect. This also removes the need for eliminating any variables from the defined list of variables. The correlation matrix presents the total variance explained by a set of factors. However, the motivation behind the factor analysis is to come up with an optimal number of factors to explain a significant portion of the variance. The high intercorrelations detected between some variables also led to the dimension reduction of the matrix.

Table 4 presents the total variance explained by components. The components are shown based on the initial Eigenvalues, variance, and cumulative variance. The table proves that the components having an Eigenvalue of greater than 1 explain the major portion of the variance, which accounts for $77.070 \%$ of the total variance. This amount is acceptable for the analysis based on the values provided in the literature [79]. Hence, a total of six components were investigated for the analysis.

Table 4. Total Variance Explained by Components.

\begin{tabular}{|c|c|c|c|c|c|c|c|c|c|}
\hline \multirow[b]{2}{*}{ Component } & \multicolumn{3}{|c|}{ Initial Eigenvalues } & \multicolumn{3}{|c|}{ Extraction Sums of Squared Loadings } & \multicolumn{3}{|c|}{ Rotation Sums of Squared Loadings } \\
\hline & Total & $\begin{array}{c}\% \text { of } \\
\text { Variance }\end{array}$ & $\begin{array}{c}\text { Cumulative } \\
\%\end{array}$ & Total & $\begin{array}{c}\% \text { of } \\
\text { Variance }\end{array}$ & $\begin{array}{c}\text { Cumulative } \\
\%\end{array}$ & Total & $\begin{array}{c}\% \text { of } \\
\text { Variance }\end{array}$ & $\begin{array}{c}\text { Cumulative } \\
\%\end{array}$ \\
\hline 1 & 9.76 & 39.041 & 39.041 & 9.760 & 39.041 & 39.041 & 4.484 & 17.935 & 17.935 \\
\hline 2 & 3.271 & 13.083 & 52.124 & 3.271 & 13.083 & 52.124 & 3.671 & 14.686 & 32.621 \\
\hline 3 & 2.488 & 9.952 & 62.076 & 2.488 & 9.952 & 62.076 & 3.499 & 13.995 & 46.615 \\
\hline 4 & 1.376 & 5.504 & 67.579 & 1.376 & 5.504 & 67.579 & 3.341 & 13.363 & 59.978 \\
\hline 5 & 1.325 & 5.301 & 72.881 & 1.325 & 5.301 & 72.881 & 2.616 & 10.462 & 70.441 \\
\hline 6 & 1.047 & 4.190 & 77.070 & 1.047 & 4.19 & 77.070 & 1.657 & 6.630 & 77.070 \\
\hline
\end{tabular}

Note: Extraction Method: Principal Component Analysis.

Table 5 shows the rotated components matrix, which was generated with the Varimax rotation method. The matrix is composed of six groups with 25 variables. The first common group is called "project and firm related factors", explaining 39,041\% of the total variance. This factor corresponds to the variables impacting the trainee performance in the success of safety training sessions. The second common group is called "demographic factors," explaining $13,083 \%$ of the total variance. The third common group is called "practical factors" explaining $9952 \%$ of the total variance. The fourth common factor group is called "motivational factors", corresponding to $5504 \%$ of the total variance. The fifth-factor group is called "organizational factors" (5301\%) focusing on the factors related to an organization in terms of affecting safety training success. Finally, the sixth-factor group is called "humanrelated factors" comprising of the variables for human-related parameters on safety training success with a variance of $4.190 \%$. The values in bold in the rotated component matrix represent the factor loadings of the variables. 
Table 5. Rotated Component Matrix.

\begin{tabular}{|c|c|c|c|c|c|c|c|}
\hline \multirow{2}{*}{ Common Factor } & \multirow{2}{*}{ Variable } & \multicolumn{6}{|c|}{ Components } \\
\hline & & 1 & 2 & 3 & 4 & 5 & 6 \\
\hline \multirow{4}{*}{$\begin{array}{l}\text { 1. Project and Firm } \\
\text { Related Factors }\end{array}$} & Project Type & 0.920 & 0.263 & 0.111 & 0.151 & 0.133 & 0.002 \\
\hline & Project Size & 0.921 & 0.267 & 0.090 & 0.139 & 0.146 & 0.011 \\
\hline & Project Duration & 0.923 & 0.243 & 0.127 & 0.110 & 0.165 & 0.014 \\
\hline & Firm Size & 0.884 & 0.325 & 0.090 & 0.158 & 0.052 & -0.008 \\
\hline \multirow{5}{*}{ 2. Demographic Factors } & Age & 0.504 & 0.769 & 0.197 & 0.077 & 0.024 & 0.043 \\
\hline & Gender & 0.390 & 0.838 & 0.169 & 0.020 & 0.078 & 0.141 \\
\hline & Country of Origin & 0.284 & 0.815 & 0.295 & 0.091 & 0.174 & 0.010 \\
\hline & Educational Background & 0.287 & 0.703 & 0.386 & -0.021 & 0.157 & -0.149 \\
\hline & Language & 0.316 & 0.509 & 0.498 & -0.039 & 0.198 & -0.361 \\
\hline \multirow{4}{*}{$\begin{array}{l}\text { 3. Practical } \\
\text { Implementation } \\
\text { Factors }\end{array}$} & Work Experience & 0.098 & 0.231 & 0.511 & 0.254 & 0.189 & -0.465 \\
\hline & Perception of Training & 0.081 & 0.179 & 0.794 & 0.160 & 0.057 & -0.165 \\
\hline & Hands-on Training & 0.048 & 0.352 & 0.838 & 0.143 & 0.069 & 0.155 \\
\hline & Methods and Materials & 0.044 & 0.070 & 0.565 & 0.187 & 0.499 & -0.103 \\
\hline \multirow{6}{*}{$\begin{array}{l}\text { 4. Organizational } \\
\text { Factors }\end{array}$} & $\begin{array}{c}\text { Safety Awareness and } \\
\text { Motivation }\end{array}$ & 0.035 & 0.496 & 0.052 & 0.559 & 0.312 & -0.268 \\
\hline & $\begin{array}{l}\text { Number of Unsafe Acts } \\
\text { and Accidents }\end{array}$ & 0.280 & 0.053 & 0.290 & 0.518 & 0.261 & 0.319 \\
\hline & Effectiveness of Training & 0.101 & 0.110 & 0.062 & 0.842 & -0.007 & -0.028 \\
\hline & $\begin{array}{l}\text { Coordination and } \\
\text { Collaboration }\end{array}$ & 0.141 & 0.015 & 0.242 & 0.689 & 0.077 & 0.331 \\
\hline & Feedback & 0.088 & 0.028 & 0.053 & 0.715 & 0.256 & 0.166 \\
\hline & Management Support & 0.319 & -0.213 & 0.339 & 0.622 & 0.199 & -0.105 \\
\hline \multirow{4}{*}{ 5. Motivational factors } & Training Satisfaction & -0.157 & 0.099 & 0.289 & 0.461 & 0.601 & 0.024 \\
\hline & Incentives for Safety & 0.268 & 0.118 & 0.102 & 0.148 & 0.825 & 0.142 \\
\hline & Training Language & 0.236 & 0.236 & 0.258 & 0.199 & 0.780 & -0.047 \\
\hline & Training Frequency & 0.223 & 0.230 & 0.724 & 0.192 & 0.187 & 0.170 \\
\hline \multirow{2}{*}{$\begin{array}{l}\text { 6. Human related and } \\
\text { behavioral factors }\end{array}$} & $\begin{array}{c}\text { Use of Personnel } \\
\text { Protective Equipment }\end{array}$ & -0.079 & 0.029 & 0.073 & 0.355 & 0.004 & 0.731 \\
\hline & Leadership & 0.198 & 0.020 & -0.179 & 0.010 & 0.438 & 0.543 \\
\hline
\end{tabular}

Note: Rotation method: Varimax with Kaiser normalization. Bold numbers represent the highest variance values.

\section{Discussion of Findings}

In this study, a total of 25 variables were determined through an in-depth literature review and interviews with safety experts to reveal the success factors for safety training sessions. Then, the factor analysis was executed to find the common factor groups. The analysis resulted in six common factor groups namely, the project and firm-related factors, demographic factors, practical factors, motivational factors, organizational factors, and human-related factors. The discussion of each factor group is presented below.

\subsection{Project and Firm Related Factors}

This factor group constitutes $39,041 \%$ of the total variance based on the data presented in Table 4. Project type (mean: 3.59), project size (mean: 3.58), and project duration (mean: 3.58) were found to be the most significant variables in this factor group with factor loadings of $0.920,0.921$, and 0.923 , respectively (Table 5). According to $75 \%$ of the survey participants, the project type, size, and duration are listed as the most important components in a successful safety training session. Teo and Feng (2009) [79] stated that project duration and size have an impact on safety culture and climate. Moreover, Jannadi and Assaf (1998) [80] explained that safety awareness differs depending on construction project size and safety practices, which is considerably lower for small-sized construction projects. Love et al. (2018) [81] further stated project type has a strong correlation with the number of injuries and accidents. This may be due to the fact that the innate nature of particular project types forces organizations to allocate more resources and attention 
to the training sessions. For instance, Kang et al. (2018) [82] implied that fall accidents are more common in residential projects than other project types. Firm Size (mean: 3.54) was determined as the fourth important variable among the other variables. Khosravi et al. (2014) [34] mentioned that firm size is directly associated with unsafe acts and accidents. Several other studies also emphasized that large-sized firms are less likely to experience unsafe acts and accidents $[45,83]$. This may be due to the fact that large-sized firms generally have more established safety management practices overall. With the evidence from previous studies and the analysis of the survey data, one may assert that project and firm-related factors have a strong effect on the success of a safety training session. Hence, both practitioners and organizations in the industry must be aware of this for their safety management practices.

\subsection{Demographic Factors}

The demographic factors strongly affect unsafe acts and accidents [34]. Moreover, Wilkins (2011) [14] stated that the demographic composition of workers is important in terms of construction safety training. According to Table 4, the demographic factors constitute $13,083 \%$ of the total variance. Among the variables of the demographic factors group, gender (mean: 3.37) was listed as the most important variable with a factor loading of 0.838. Loosemore and Malouf (2019) [61] underlined that gender differences are of great importance for the improvement of accident prevention strategies such as safety training. Gender might also act as a parameter to discriminate between the severity levels of work accidents [84].

Country of origin (mean: 3.35) was determined as the second most important variable among demographic factors with a factor loading of 0.815. Mahalingam and Levitt (2007) stated that the origin country of workers is an important factor in construction safety due to cultural differences. Some other studies implied that immigrant workers are more likely to be involved in accidents than local workers [85,86]. Byler (2013) [87] found that the number of fatal accidents is $66 \%$ higher for Latin American workers who are foreign-born than for US-born ones. Hence, one may claim that country of origin is an essential factor needing careful consideration for safety training sessions.

Age (mean: 3.32) is the third most important variable with a factor loading of 0.769 . Khosravi et al. (2015) [34] stated that age is closely related to the number of unsafe acts and accidents. Khodabandeh et al., 2016 [84] indicated that the age of workers might be investigated to distinguish between different severity levels of work accidents. Kale and Baradan (2020) [39] emphasized that the frequency of work injuries decreases as the age of workers increases. According to Zhang and An (2012) [88], as workers grow older, safety observation and intelligibility decrease. Moreover, Lossemore and Malouf (2019) [61] underlined that older workers are less motivated by the safety training than other age groups. Hence, safety training content and approaches tailored for different age groups should be considered.

The educational background (mean: 3.77) of workers was determined as the fourth important variable (factor loading: 0.703). Educational background is one of the essential factors for the formation of risk perception [89-91]. Some other studies found that the educational background of construction workers is directly related to safety awareness [82,85]. Given this background, educational background is considered as an important factor affecting the success of safety training. Thus, one may advocate that as educational level increases, safety awareness becomes higher.

Finally, language (mean: 3.68; factor loading: 0.509) of workers was determined as the last important variable among the demographic factors. Keng and Razak (2014) [62] reported that one of the problems in safety applications on construction sites is the language barrier among workers. However, immigrant workers might be motivated to conduct bilingual safety training [62]. Hence, language is an important factor that needs to be carefully considered in safety training sessions to increase the success of safety training. 


\subsection{Practical Implementation Factors}

The practical implementation factors constitute $9.952 \%$ of the total variance as shown in Table 4. Among this factor group, hands-on training (mean: 4.69; factor loading: 0.838) was determined as the first important variable. Burke et al. (2006) [92] reported that safety training becomes more effective with hands-on training. According to [58], instructors of safety training must try to develop not only traditional paper-based but also on-site assessment and engagement techniques. Cameron et al. (2011) [93] indicated that learning methods driven by visual cues and tools facilitate safety training. Since handson-training provides a practical dimension for safety, it has the potential to increase safety training success.

Perception of training (mean: 4.60; factor loading: 0.794) was found to be the second important variable of the practical factors. According to $97 \%$ of the survey participants, the perception of training constitutes an important place in safety training implementation. Mushayi et al. (2018) [94] highlighted that employees' perceptions of health and safety training create a considerable impact on their health and safety behavior and compliance. Demirkesen and Arditi (2015) [3] also highlighted the importance of safety training perception in developing a safe behavior. Employees perceiving the benefits of training sessions have the potential to develop safe behavior and avoid themselves from being involved in hazardous situations. They may also pay better attention during the sessions. Therefore, developing a positive safety training perception is a critical variable in terms of conducting more effective safety training and must be considered by safety professionals.

Methods and materials (mean: 4.90; factor loading: 0.565) were determined as the fourth important variable of the practical factors. Jeelani et al. (2017) [51] revealed that there is a great need to improve the methods and efficiency for safety training. Hussain et al. (2018) [58] reported that a minor increase in training transfer results in a major increase in workers' safety performance. Therefore, authorities should focus on additional methods to maximize the level of safety training [58]. Tam and Fung (2012) [43] stated that alternative training methods should be included in safety training sessions. They further mentioned that different methods (such as multimedia aids) should be used in safety training sessions to provide a more effective training and attract participants' attention. Jeelani et al. (2017) [51] recommend realistic and immersive training environments to improve the efficiency of safety training. Furthermore, safety procedures must be well written and understandable to all workers [43]. Hence, the methods and materials used in training sessions should be wisely selected and implemented to attract workers' interest in safety training. This is also linked with workers' perception of safety training.

Work experience (mean: 4.41; factor loading: 0.511) of workers was determined as the fifth important variable on the rotated component matrix. Previous studies proved that the experience of workers affects work safety and safety perception. In Hare et al. (2013)'s study [71], it was found that there are significant differences among workers in terms of understanding safety pictures. They further indicated that workers with more than 5 years of experience were successful in defining safety pictures than those with less experience. According to [39], the possibility of work injuries decreases as the experience of workers increases. Aligned with these studies, it is of utmost importance to grow experience in safety and safe practices in parallel to the experience in construction. Therefore, one needs to carefully consider the impact of the experience of trainees on safety training success while tailoring safety training sessions.

\subsection{Organizational Factors}

The organizational factors constitute $5.504 \%$ of the total variance as shown in Table 4 . Effectiveness of training (mean: 4.83; factor loading: 0.842) was determined as the first important variable explaining the motivational factors group. Haslam et al. (2005) [95] stated that poor safety knowledge is the main cause of at least $70 \%$ of the accidents on construction sites. According to [58], effective training increases workers' knowledge of safety. Moreover, it was further implied that effective training practices and training 
transfer elements should be adopted together to maximize risk perception and hazard recognition [41,42]. Demirkesen and Arditi (2015) [3] underlined that necessary attention must be given to the effectiveness of learning in training sessions to improve construction site safety. Tam and Fung (2012) [43] further mentioned that training content and methods must be carefully designed and reevaluated when necessary to increase the effectiveness of training sessions. As proven by the previous studies, increasing the effectiveness of training is one of the critical elements to provide a more successful safety training session. This variable should be considered carefully by practitioners and organizations.

Feedback (mean: 4.83; factor loading: 0.715) was determined as the second important variable explaining the motivational factor group. Providing feedback is critical to improving the safety performance of workers [26,96]. Lai et al. (2011) [26] reported that feedback is an important reminder to workers about their unsafe acts. Demirkesen and Arditi (2015) [3] also mentioned that feedback is one of the most essential components of effective safety training. Therefore, safety trainers must ensure having effective feedback mechanisms in their safety training programs.

Coordination and collaboration (mean: 4.74; factor loading: 0.689) was determined as the third important variable of the motivational factors. According to $99 \%$ of the survey participants, coordination and collaboration play a critical role in safety training implementation. Sun et al. (2017) [50] showed that construction firms will not be able to provide vocational (skill and safety) training without government involvement concluding that the government, workers, professional organizations, and firms need to cooperate for vocational training. A good coordination and a collaborative environment lead to effective safety training sessions, allowing trainees to better conceive the essence of a training session, where they feel empowered and motivated to learn about safety.

Management support (mean: 4.71; factor loading: 0.662 ) was found to be the fourth important variable of the motivational factors group. Keng and Razak (2014) [62] reported that the problems on construction sites usually stem from the lack of safety awareness and financial resources for safety management. Copper (2006) [97] indicated that safety performance is better when management support is high. Several studies have already highlighted the critical role of management commitment to reducing the number of safety-related accidents $[26,32,34,98-100]$. As evidenced by previous studies, management support is critical in terms of creating a workplace safety culture and promoting safety training practices. Therefore, firms aiming to increase their safety performance through training sessions must beware of the fact that they need to commit to safety management programs with full support.

Safety awareness and motivation (mean: 4.91; factor loading: 0.559) was found to be the fifth important variable of the motivational factors. A major portion of the survey respondents indicated that safety awareness and motivation constitute an important part of safety training implementation. Namian et al. (2016) [41] found that motivation is one of the necessary transfer elements for hazard recognition and safety training. Demirkesen and Arditi (2015) [3] expressed that large construction firms in the U.S.A. are responsive to worker issues such as motivating workers and raising awareness for safety. Kim (2009) [91] showed that worker personality affects safety awareness of construction workers. Hence, safety awareness and motivation are essential elements in achieving a successful safety training session. Trainees would better learn in an environment, where awareness for safety is raised and motivation is promoted.

The number of unsafe acts and accidents (mean: 4.62; factor loading: 0.518) was determined as the last important variable of the motivational factors. Kale and Baradan (2020) [33] showed that unsafe conditions and unsafe acts influence work injury severity. Hence, awareness of unsafe acts and accident numbers leads trainees to being alerted during safety training sessions. Moreover, trainees would better concentrate during training sessions, where the number of unsafe acts and accidents are presented in the training sessions. This raises the potential for taking preventive measures towards a specific type of accident or develop measures for different unsafe acts. 


\subsection{Motivational Factors}

The organizational factors constitute $5.301 \%$ of the total variance as presented in Table 4. Incentives for safety (mean, 4.65; factor loading: 0.825) was found to be the first important variable of the organizational factors. Khosravi et al. (2015) [34] mentioned that incentives are directly associated with unsafe acts and accidents. Sectoral incentives such as rewards and punishments encourage construction firms to provide vocational (skill and safety) training [50]. Teo et al. (2005) [98] concluded that one of the most important factors affecting construction site safety is the incentives. Hence, the presence of incentives deserves special emphasis to raise motivation for safety training and to increase the effectiveness of training sessions. Firms seriously considering incentives to reward workers for their safe behavior are more likely to experience enhanced safety performance. Thus, organizations should take incentives into account and consider having an incentive structure linked with their safety training programs.

Training language (mean: 4.61; factor loading: 0.780) was found to be the second important variable for the organizational factors group. A significant portion of studies in the literature proves that immigrant construction workers experience difficulties in understanding the language of training in safety training sessions. Demirkesen and Arditi (2015) [3] advocated that safety training participants' language problems in their training sessions might be solved using translators and visual aids. Moreover, Hussain et al. (2018) [58] proposed that immigrant workers can be encouraged to go through bilingual safety training provided their firms are able to offer such training opportunities.

Training frequency (mean: 4.54; factor loading: 0.724) was determined as the third important variable of the practical factors. Pandit et al. (2019) [60] emphasized that a positive safety climate affects construction workers' perception of risk, leading to increased awareness for risks and hazards. Furthermore, as the frequency of training increases, construction workers' attitude towards safer practices changes positively [55]. Tam and Fung (2012) [43] further implied that regular training is essential for promoting safety and positively affecting workers' safety behavior. Therefore, regular/frequent safety training arrangements must be considered carefully.

Training satisfaction (mean: 4.86; factor loading: 0.601) was found to be the third important variable of the organizational factors group. The statistics obtained from this research showed that $95 \%$ of the participants in the study, who are mostly managers, indicated that they are satisfied with the safety training they had before. Nevertheless, Wilkins (2011) [14] evaluated the satisfaction of construction workers with safety training and stated that a high proportion of workers are actually not satisfied with the training provided to them. Moreover, Lossemore and Malouf (2019) [61] mentioned that there are minimum positive changes in workers' behavioral intentions before and after safety training, indicating that workers' emotional engagement with safety is high at the beginning of the safety training. Hence, it is essential that trainees are satisfied with the training provided to them so that they commit to the training efforts. Measuring the training satisfaction during or after a safety training session and acting for change and improvement are critical to tailor effective training sessions. Because training satisfaction is a variable affecting training success, it is of greater importance to show efforts in measuring training satisfaction.

\subsection{Human Related and Behavioral Factors}

The final factor group is the human-related and behavioral factors, which constitute $4.190 \%$ of the total variance. This factor consists of the use of personnel protective equipment (PPE) (mean: 4.95; factor loading: 0.731) and leadership (mean: 4.92; factor loading: 0.543) variables. According to all survey participants, using PPE and leadership have high importance in safety training implementation. Previous studies also show the importance of these two factors in construction safety. Yap and Lee (2019) [33] stated that the most critical variable for safety awareness is the use of PPE. Wu et al. (2017) [101] revealed that leadership positively affects construction safety management. The use of PPE in training sessions is a way to demonstrate to trainees how life-saving equipment 
might be correctly used. This would reinforce the safety knowledge of the trainees leading to a visual representation of what needs to be done on-site. By utilizing PPE in training sessions, one might increase the session's success. Leadership is another essential variable in terms of affecting the success of safety training. Leaders are people who have the potential to affect a broad community with essential safety information by championing safety and setting an example. Good leadership results in good practice and enhanced safety performance. Consequently, training success would be higher in the existence of good leaders and leadership skills.

\section{Conclusions}

The construction industry suffers from a high number of work-related injuries and accidents. Even though various efforts have been put in place to eliminate work-related accidents, there still needs to be serious measures to completely protect workers from being involved in hazardous situations. One of the most commonly utilized efforts in this respect is safety training provided within an organization. Knowing this great potential for preventing work-related injuries and fatalities, organizations must develop ways to improve their safety programs and specifically, their safety training sessions. However, there are still difficulties in designing effective safety training sessions and enhancing safety performance through these sessions. Especially, different learning styles of construction workers render safety trainings more challenging and risk their safety knowledge gained through those trainings. One other concern is that the workers are not still motivated and fostered towards employing safeguards such as use of PPE, following safety standards, and stopping the line in unsafe situations. The language barrier also presents a critical risk for foreign workers, leading to poor safety learning. Therefore, this study explores the CFs for effective safety training sessions for the construction industry. In this respect, a total of 25 variables were identified for the success of safety training based on an in-depth literature review and interviews with safety experts. Then, a survey was designed and administered to the ENR Top 400 Contractors List. The survey participants were selected from this group since the top contractors are the ones that provide regular safety training to their employees. The survey resulted in a response rate of $23 \%$. This study targets the responses provided by the top contractors for the fact that their successful practices become examples to those aiming to promote their safety programs. Moreover, the study puts safety training to the forefront of safety programs since different learning styles leading to safe and unsafe acts are best observed during training sessions.

Based on the analyses of the survey responses, it was found that most of the responses were collected from construction professionals having over 20 years of experience in the construction industry. The respondents also reported that they are highly satisfied with the previous safety training they had and implied that safety training helped them increase their safety awareness. The respondents further mentioned that they were trained with different safety training methods such as computer-based training, on-the-job training, and equipment-use simulation. For the safety training success variables, the factor analysis was executed to group the factors and name them accordingly. The analyses of the factors resulted in six-factor groups, namely the project and firm-related factors, demographic factors, practical factors, motivational factors, organizational factors, and human-related factors. Among the factor groups, project and firm-related factors were found to be the most influential factors for safety training success. This factor group consists of variables such as project type, project size, project duration, and firm size. The other factor groups were also found to be significant, but their relative importance is lower compared to the project and firm related factors group.

The motivation behind this study is to assess the factors leading to a higher success in safety training sessions for the fact that effective training provides trainees with better safety performance, eventually reducing work-related injuries and fatalities. Since this is a serious concern in the construction industry, the investigation of the parameters affecting safety performance plays a critical role in rendering a better safety performance. To this end, 
the results of this study are expected to guide construction industry practitioners in terms of reviewing their safety programs and revise their safety training assessment accordingly. This also contributes to the reputation of an organization and increases their work reliability. However, this study has also some limitations as the results generated are based on the perceptions and experiences of the 400 Top Contractors in the U.S. The results could differ with another data set collected in a different region. Moreover, the survey was conducted with a relatively small sample reflecting the perceptions of a small group. On the other hand, the results are generalizable since the 400 Top Contractors are industry leaders with their well-developed safety programs and safety management experience. Hence, their insights into safety training might provide a roadmap for a broader community. As future work, the results of this study might lead researchers to investigate safety training practices in other countries/regions and the results might be compared. Similar studies focusing on different firm sizes and project types might be useful. Moreover, the performance of safety training sessions from both the trainer's and trainee's perspectives might be assessed. The success factors provided in this study might be used to assess whether firms considering these parameters in designing their safety training perform better or not.

Author Contributions: Conceptualization, A.T. and S.D., Methodology, I.A.K. and E.D., WritingOriginal Draft Preparation, A.T., Writing-Review \& Editing, S.D., I.A.K., E.D. All authors have read and agreed to the published version of the manuscript.

Funding: This research received no external funding.

Institutional Review Board Statement: Not applicable.

Informed Consent Statement: Not applicable.

Data Availability Statement: The data presented in this study are available on request from the corresponding author. The data are not publicly available due to privacy and ethical restrictions.

Conflicts of Interest: The authors declare no conflict of interest.

\section{Appendix A}

Survey of critical success factors in safety training

1. Please indicate your age

2. Please indicate your gender.

_Female__Male

3. Please indicate your country of origin

4. Please indicate your level of education.

_ Master- PhD

_Degree

_Diploma/Certificate

_ Secondary

Primary

5 . How long has your company been operating in the construction industry?

- $0-5$ years

- 5-10 years

-10-15 years

_15-20 years

_.Above 20 years

6. What is the total turnover of your company (in Million USD)

7. What is the total number of employees in your company? 
8. Please indicate the importance level of below listed factors in the success of safety training implementation.

\begin{tabular}{|c|c|c|c|c|c|}
\hline Variables & Very Low & Low & Medium & High & Very High \\
\hline \multicolumn{6}{|l|}{ Age } \\
\hline \multicolumn{6}{|l|}{ Gender } \\
\hline \multicolumn{6}{|l|}{ Country of Origin } \\
\hline \multicolumn{6}{|c|}{ Educational Background } \\
\hline \multicolumn{6}{|l|}{ Language } \\
\hline \multicolumn{6}{|l|}{ Work Experience } \\
\hline \multicolumn{6}{|c|}{ Perception of Training } \\
\hline \multicolumn{6}{|l|}{ Hands-on Training } \\
\hline \multicolumn{6}{|l|}{ Training frequency } \\
\hline \multicolumn{6}{|c|}{ Methods and Materials } \\
\hline \multicolumn{6}{|c|}{ Training Satisfaction } \\
\hline \multicolumn{6}{|c|}{ Safety awareness and motivation } \\
\hline \multicolumn{6}{|c|}{ Number of unsafe acts and accidents } \\
\hline \multicolumn{6}{|c|}{ Effectiveness of training } \\
\hline \multicolumn{6}{|c|}{ Coordination and collaboration } \\
\hline \multicolumn{6}{|l|}{ Feedback } \\
\hline \multicolumn{6}{|c|}{ Management support } \\
\hline \multicolumn{6}{|c|}{$\begin{array}{l}\text { Use of Personnel Protective } \\
\text { Equipment }\end{array}$} \\
\hline \multicolumn{6}{|l|}{ Leadership } \\
\hline \multicolumn{6}{|l|}{ Project type } \\
\hline \multicolumn{6}{|l|}{ Project size } \\
\hline \multicolumn{6}{|l|}{ Project duration } \\
\hline \multicolumn{6}{|l|}{ Firm size } \\
\hline \multicolumn{6}{|l|}{ Incentives for safety } \\
\hline Training language & & & & & \\
\hline
\end{tabular}

9. Have you ever been involved in a safety training session? If so, how many times?

- Yes _No

_1-3_3-5_More than 5 times

10. Did you have any problem to understand the language of safety training?

_Yes__Partly_No

11. How long have you been working in the construction industry?

- $0-5$ years

-6-10 years

_11-15 years

_16-20 years

_Above 20 years

12. Were realistic examples from construction sites provided during safety training sessions that you attended?

-Yes _ 
13. How long was the duration of the training you got?

14. Which methods of training were used during the sessions?

_Computer based training

_Equipment use simulation

_Games and simulations

_On the Job Training

_Behavior order

__Improving behavior

__ensitivity Training

15. What is your satisfaction level with your safety training?

_Very low __Low _ _Medium_High_ _ _ _ High

16. Do you think you need motivation to eliminate unsafe behavior?

-Yes - No

17. Have you ever involved in a work-related accident? If so, how did the training affect your chance of being involved in a work-related accident?

18. Did training increase your ability to detect unsafe acts or behaviors? If so, what were the main unsafe acts or behaviors you observed?

19. Did the training help increase your safety awareness? If so, what percent of increase would you specify for the awareness?

_. $\% 10$ and less

- $\% 11-\% 30$

- $\% 31-\% 50$

- $\% 51-\% 70$

_ $\% 71$ and more

20. Would you be willing to get more safety trainings for increasing your safety performance?

-Yes _No

\section{References}

1. Toscano, G.; Windau, J.; Drudi, D. Using the BLS Occupational Injury and Illness Classification System as a Safety and Health Management Tool. Compens. Work. Cond. 1996, 6, 19-28.

2. Goldenhar, L.M.; Moran, S.K.; Colligan, M. Health and safety training in a sample of open-shop construction companies. J. Saf. Res. 2001, 32, 237-252. [CrossRef]

3. Demirkesen, S.; Arditi, D. Construction safety personnel's perceptions of safety training practices. Int. J. Proj. Manag. 2015, 33, 1160-1169. [CrossRef]

4. Center to Protect Workers Rights (CPWR). The Construction Chart Book: The U.S Construction Industry and Its Workers, 6th ed.; The Center for Construction Research and Training: Silver Spring, MD, USA, 2018.

5. Lette, A.; Ambelu, A.; Getahun, T.; Mekonen, S. A survey of work-related injuries among building construction workers in southwestern Ethiopia. Int. J. Ind. Ergon. 2018, 68, 57-64. [CrossRef]

6. Bureau of Labor Statistics (BLS). National Census of Fatal Occupational Injuries in 2018. 2018. Available online: https://www.bls. gov/news.release/pdf/cfoi.pdf (accessed on 1 April 2020).

7. Chen, A.; Golparvar-Fard, M.; Kleiner, B. SAVES: A safety training augmented virtuality environment for construction hazard recognition and severity identification. In Proceedings of the 13th International Conference on Construction Applications of Virtual Reality, London, UK, 30-31 October 2013.

8. Heinrich, H. Industrial Accident Prevention; McGraw-Hill: New York, NY, USA, 1931.

9. Bird, F.; Germain, G. Practical Loss Control Leadership; ILCI Press: Logansville, CA, USA, 1990.

10. Alarcón, L.F.; Acuña, D.; Diethelm, S.; Pellicer, E. Strategies for improving safety performance in construction firms. Accid. Anal. Prev. 2016, 94, 107-118. [CrossRef]

11. Durdyev, S.; Mohamed, S.; Lay, M.L.; Ismail, S. Key factors affecting construction safety performance in developing countries: Evidence from Cambodia. Constr. Econ. Build. 2017, 17, 48-65. [CrossRef]

12. Øien, K.; Utne, I.B.; Herrera, I.A. Building Safety indicators: Part 1-Theoretical foundation. Saf. Sci. 2011, 49, 148-161. [CrossRef] 
13. Guo, B.H.W.; Yiu, T.W.; González, V.A. Predicting safety behavior in the construction industry: Development and test of an integrative model. Saf. Sci. 2016, 84, 1-11. [CrossRef]

14. Wilkins, J.R. Construction workers' perceptions of health and safety training programmes. Constr. Manag. Econ. 2011, 29, 1017-1026. [CrossRef]

15. Zin, S.M.; Faridah, I. Employers' behavioural safety compliance factors toward occupational, safety and health improvement in the construction industry. Procedia Soc. Behav. Sci. 2012, 36, 742-751. [CrossRef]

16. Haadir, S.A.; Panuwatwanich, K. Critical success factors for safety program implementation among construction companies in Saudi Arabia. Procedia Eng. 2011, 14, 148-155. [CrossRef]

17. Tam, C.; Zeng, S.; Deng, Z. Identifying elements of poor construction safety management in China. Saf. Sci. 2004, 4, 569-586. [CrossRef]

18. Rodríguez-Garzón, I.; Lucas-Ruiz, V.; Martínez-Fiestas, M.; Delgado-Padial, A. Association between perceived risk and training in the construction industry. J. Constr. Eng. Manag. 2015, 141, 453-468. [CrossRef]

19. Wong, T.K.M.; Man, S.S.; Chan, A.H.S. Critical factors for the use or non-use of personal protective equipment amongst construction workers. Saf. Sci. 2020, 126, 104663. [CrossRef]

20. Wong, T.K.M.; Man, S.S.; Chan, A.H.S. Exploring the acceptance of PPE by construction workers: An extension of the technology acceptance model with safety management practices and safety consciousness. Saf. Sci. 2021, 139, 105239. [CrossRef]

21. Hasanzadeh, S.; De La Garza, J.M.; Geller, E.S. Latent effect of safety interventions. J. Constr. Eng. Manag. 2020, 146, 04020033. [CrossRef]

22. Reiman, A.; Pedersen, L.M.; Väyrynen, S.; Sormunen, E.; Airaksinen, O.; Haapasalo, H.; Räsänen, T. Safety training parkscooperative contribution to safety and health trainings. Int. J. Constr. Educ. Res. 2019, 15, 19-41. [CrossRef]

23. Man, S.S.; Chan, A.H.S.; Alabdulkarim, S. Quantification of risk perception: Development and validation of the construction worker risk perception (CoWoRP) scale. J. Saf. Res. 2019, 71, 25-39. [CrossRef]

24. Abdelhamid, T.S.; Everett, J.G. Identifying root causes of construction accidents. J. Constr. Eng. Manag. 2000, 126, 52-60. [CrossRef]

25. Rahim, A.A.H.; Zaimi, M.A.M.; Singh, B. Causes of Accidents at Construction Sites. Malays. J. Civ. Eng. 2008, 20, $242-259$.

26. Lai, D.N.C.; Liu, M.; Ling, F.Y.Y. A comparative study on adopting human resource practices for safety management on construction projects in the United States and Singapore. Int. J. Proj. Manag. 2011, 29, 1018-1032. [CrossRef]

27. Hinze, J.; Thurman, S.; Wehle, A. Leading indicators of construction safety performance. Saf. Sci. 2013, 51, 23-28. [CrossRef]

28. Fang, D.; Wu, H. Development of a safety culture interaction (SCI) model for construction projects. Saf. Sci. 2013, 57, 138-149. [CrossRef]

29. Mroszczyk, J.W. Improving construction safety: A team effort. Constr. Saf. 2015, 60, 55-68.

30. Fang, D.; Jiang, Z.; Zhang, M.; Wang, H. An experimental method to study the effect of fatigue on construction workers' safety performance. Saf. Sci. 2015, 73, 80-91. [CrossRef]

31. Okoye, P.U. Improving the safety performance of Nigeria construction workers: A social ecological approach. Univers. J. Eng. Sci. 2016, 4, 22-37. [CrossRef]

32. Aksorn, T.; Hadikusumo, B.H.W. Critical success factors influencing safety program performance in Thai construction projects. Saf. Sci. 2008, 46, 709-727. [CrossRef]

33. Yap, J.B.H.; Lee, W.K. Analysing the underlying factors affecting safety performance in building construction. Prod. Plan. Control 2019. [CrossRef]

34. Khosravi, Y.; Asilian-Mahabadi, H.; Hajizadeh, E.; Hassanzadeh-Rangi, N.; Bastani, H.; Behzadan, A.H. Factors influencing unsafe behaviors and accidents on construction sites: A Review. Int. J. Occup. Saf. Ergon. 2014, 20, 111-125. [CrossRef]

35. Khan, K.M.I.; Suguna, K.; Raghunath, P.N. A Study on safety management in construction projects. Int. J. Eng. Sci. Innov. Technol. (IJESIT) 2015, 4, 119-128.

36. Wang, J.; Zou, P.X.W.; Li, P.P. Critical factors and paths influencing construction workers' safety risk tolerances. Accid. Anal. Prev. 2016, 93, 267-279. [CrossRef]

37. Ismail, F.; Ahmad, N.; Janipha, N.A.; Ismail, R. Assessing the behavioural factors' of safety culture for the Malaysian construction companies. Procedia Soc. Behav. Sci. 2012, 36, 573-582. [CrossRef]

38. Ismail, Z.; Doostdar, S.; Harun, Z. Factors influencing the implementation of a safety management system for construction sites. Saf. Sci. 2011, 50, 418-423. [CrossRef]

39. Kale, O.A.; Baradan, S. Identifying factors that contribute to severity of construction injuries using logistic regression model. Tek. Dergi 2020, 573, 9919-9940.

40. Sollis-Carcadio, R.G.; Franco-Poot, R.J. Construction workers' perception of safety practices: A case study in Mexico. J. Build. Constr. Plan. Res. 2014, 2, 1-11. [CrossRef]

41. Namian, M.; Albert, A.; Zuluaga, C.M.; Behm, M. Role of safety training: Impact on hazard recognition and safety risk perception. J. Constr. Eng. Manag. 2016, 04016073. [CrossRef]

42. Zuluaga, C.M.; Namian, M.; Albert, A. Impact of training methods on hazard recognition and risk perception in construction. In Proceedings of the Construction Research Congress, San Juan, Puerto Rico, 31 May-2 June 2016; pp. 2861-2871.

43. Tam, V.; Fung, I. Behavior, attitude, and perception toward safety culture from mandatory safety training course. J. Prof. Issues Eng. Educ. Pract. 2012, 138, 207-213. [CrossRef] 
44. Ho, C.L.; Dzeng, R.J. Construction safety training via e-Learning: Learning effectiveness and user satisfaction. Comput. Educ. 2010, 55, 858-867. [CrossRef]

45. Kaskutas, V.; Dale, A.M.; Lipscomb, H.; Evanoff, B.A. Fall prevention and safety communication training for foremen: Report of a pilot project designed to improve residential construction safety. J. Saf. Res. 2013, 44, 111-118. [CrossRef] [PubMed]

46. Sacks, R.; Perlman, A.; Barak, R. Construction safety training using immersive virtual reality. Constr. Manag. Econ. 2013, 31, 1005-1017. [CrossRef]

47. Lin, K.; Migliaccio, G.; Azari, R.; Lee, C.; De la Llata, J. Developing 3D Safety Training Materials on Fall Related Hazards for Limited English Proficiency (LEP) and Low Literacy (LL) Construction Workers. In Proceedings of the International Conference on Computing in Civil Engineering, Clearwater Beach, FL, USA, 17-20 June 2012; pp. 113-120.

48. Chen, A.; Golparvar-Fard, M.; Kleiner, B. Design and Development of SAVES: A Construction Safety Training Augmented Virtuality environment for hazard recognition and severity identification. In Proceedings of the International Conference on Computing in Civil Engineering, Los Angeles, CA, USA, 23-25 June 2013; pp. 841-848.

49. Zhao, D.; Lucas, J. Virtual reality simulation for construction safety promotion. Int. J. Inj. Control Saf. Promot. 2015, 22, 57-67. [CrossRef]

50. Sun, J.; Wang, X.; Shen, L. Chinese construction workers' behaviour towards attending vocational skills trainings: Evolutionary game theory with government participation. J. Differ. Equ. Appl. 2017, 23. [CrossRef]

51. Jeelani, I.; Han, K.; Albert, A. Development of immersive personalized training environment for construction workers. In Proceedings of the Congress on Computing in Civil Engineering, Seattle, WA, USA, 25-27 June 2017; pp. 408-415.

52. Li, X.; Yi, W.; Chi, H.L.; Wang, X.; Chan, A.P. A critical review of virtual and augmented reality (VR/AR) applications in construction safety. Autom. Constr. 2018, 86, 150-162. [CrossRef]

53. Williams, Q., Jr.; Ochsner, M.; Marshall, E.; Kimmel, L.; Martino, C. The impact of a peer-led participatory health and safety training program for Latino day laborers in construction. J. Saf. Res. 2010, 41, 253-261. [CrossRef]

54. Han, S.H.; Park, S.H.; Jin, E.J.; Kim, Y.K.; Seong, Y.K. Critical issues and possible solutions for motivating foreign construction workers. J. Manag. Eng. 2008, 24, 217-226. [CrossRef]

55. O'Connor, T.; Loomis, D.; Runyan, C.; Santo, J.A.; Schulman, M. Adequacy of health and safety training among young Latino construction workers. J. Occup. Environ. Med. 2005, 47, 272-277. [CrossRef]

56. Arnold, J.; Silvester, J.; Patterson, F.; Robertson, I.; Cooper, C.; Burnes, B. Work psychology. In Understanding Human Behaviour in the Workplace, 4th ed.; Pearson Education Limited: Essex, UK, 2005.

57. Freitas, A.C.; Silva, S.A.; Santos, C.M. Safety training transfer: The roles of coworkers, supervisors, safety professionals, and felt responsibility. J. Occup. Health Psychol. 2019, 24, 92-107. [CrossRef]

58. Hussain, R.; Pedro, A.; Lee, D.Y.; Pham, H.C.; Park, C.S. Impact of safety training and interventions on training-transfer: Targeting migrant construction workers. Int. J. Occup. Saf. Ergon. 2018. [CrossRef]

59. McGlothlin, J.; Hubbard, B.; Aghazadeh, F.; Hubbard, S. Ergonomics. J. Occup. Environ. Hyg. 2009, 6, 45-50. [CrossRef] [PubMed]

60. Pandit, B.; Albert, A.; Patil, Y.; Al-Bayati, A. Impact of safety climate on hazard recognition and safety risk perception. Saf. Sci. 2019, 113, 44-53. [CrossRef]

61. Loosemore, M.; Malouf, N. Safety training and positive safety attitude formation in the Australian construction industry. Saf. Sci. 2019, 113, 233-243. [CrossRef]

62. Keng, T.C.; Razak, N.A. Case studies on the safety management at construction site. J. Sustain. Sci. Manag. 2014, 9, 90-108.

63. Teck, A.G.P.; Asmoni, M.N.A.; Misnan, M.S.; Jaafar, M.N.; Mei, J.L.Y. A review on the effectiveness of safety training methods for Malaysia construction industry. J. Teknol. 2015, 74, 9-13. [CrossRef]

64. Namian, M.; Albert, A.; Zuluaga, C.M.; Jaselskis, E.J. Improving hazard-recognition performance and safety training outcomes: Integrating strategies for training transfer. J. Constr. Eng. Manag. 2016, 142, 1-11. [CrossRef]

65. Robson, L.; Stephenson, C.; Schulte, P.; Amick, B.; Chan, S.; Bielecky, A.; Wang, A.; Heidotting, T.; Irvin, E.; Eggerth, D.; et al. A Systematic Review of the Effectiveness of Training \& Education for the Protection of Workers. 2010. Available online: http:/ / www.mtpinnacle.com/pdfs/2010-127.pdf (accessed on 1 April 2020).

66. Cunningham, T.R.; Guerin, R.J.; Keller, B.M.; Flynn, M.A.; Salgado, C.; Hudson, D. Differences in safety training among smaller and larger construction firms with non-native workers: Evidence of overlapping vulnerabilities. Saf. Sci. 2018, 103, 62-69. [CrossRef] [PubMed]

67. Burke, M.; Smith-Crowe, K.; Salvador, R.; Chan-Serafin, S.; Smith, A.; Sonesh, S. The dread factor: How hazards and safety training influence learning and performance. J. Appl. Psychol. 2011, 96, 46-70. [CrossRef]

68. Saurin, T.A.; Formoso, C.T.; Cambraia, F.B. An analysis of construction safety best practices from a cognitive systems engineering perspective. Saf. Sci. 2008, 46, 1169-1183. [CrossRef]

69. BLR. 50 Tips for More Effective Safety Training; Special Report, Business; Legal Reports. Inc.: Nashville, TN, USA, 2007.

70. Abbas, M.; Mneymneh, B.E.; Khoury, H. Assessing onsite construction personnel hazard perception in a Middle Eastern developing country: An interactive graphical approach. Saf. Sci. 2018, 103, 183-196. [CrossRef]

71. Hare, B.; Cameron, I.; Real, K.J.; Maloney, W.F. Exploratory case study of pictorial aids for communicating health and safety for migrant construction workers. J. Constr. Eng. Manag. 2013, 139, 818-825. [CrossRef]

72. Engineering News-Record (ENR). ENR 2019 Top 400 Contractors: The Market Keeps Growing. 2020. Available online: https: //www.enr.com/articles/46942-enr-2019-top-400-contractors-the-market-keeps-growing (accessed on 22 December 2019). 
73. Salem, O.; Solomon, J.; Genaidy, A.; Luegring, M. Site implementation and assessment of lean construction techniques. Lean Constr. J. 2005, 2, 1-21.

74. Comrey, A.L.; Lee, H.B. A First Course in Factor Analysis; Psychology Press: New York, NY, USA, 2013.

75. Kleinbaum, D.G.; Kupper, L.L.; Nizam, A.; Rosenberg, E.S. Applied Regression Analysis and other Multivariable Methods; Nelson Education: Boston, MA, USA, 2013.

76. Hair, J.F.; Black, W.C.; Babin, B.J.; Anderson, R.E.; Tatham, R. Multivariate Data Analysis; Pearson: Uppersaddle River, NJ, USA, 2006.

77. Field, A. Discovering Statistics Using IBM SPSS Statistics; SAGE Publications: London, UK, 2013.

78. Field, A. Discovering Statistics Using SPSS, 2nd ed.; SAGE Publications: London, UK, 2005.

79. Teo, E.A.L.; Feng, Y. The role of safety climate in predicting safety culture on construction sites. Archit. Sci. Rev. 2009, 52, 5-16. [CrossRef]

80. Jannadi, M.O.; Assaf, S. Safety assessment in the built environment of Saudi Arabia. Saf. Sci. 1998, 29, 15-24. [CrossRef]

81. Love, P.E.D.; Teo, P.; Morrison, J. Unearthing the nature and interplay of quality and safety in construction projects: An empirical study. Saf. Sci. 2018, 103, 270-279. [CrossRef]

82. Kang, Y.; Siddiqui, S.; Suk, S.J.; Chi, S. Trends of fall accidents in the U.S. construction industry. J. Constr. Eng. Manag. 2017, 143, 04017043. [CrossRef]

83. Sa, J.; Seo, D.C.; Choi, S.D. Comparison of risk factors for falls from height between commercial and residential roofers. J. Saf. Res. 2009, 40, 1-6. [CrossRef] [PubMed]

84. Khodabandeh, F.; Mokamelkhah, E.K.; Kahani, M. Factors associated with the severity of fatal accidents in construction workers. Med. J. Islamic Repub. Iran (Mjiri) 2016, 30, 4691-4697.

85. Orrenius, P.M.; Madeline, Z. Do immigrants work in riskier jobs? Demography 2009, 46, 535-551. [CrossRef]

86. Hersch, J.; Viscusi, W.K. Immigrant status and the value of statistical life. J. Hum. Resour. 2010, 45, 749-771.

87. Byler, C.G. Hispanic/Latino Fatal Occupational Injury Rates. Fatal Injuries to Hispanic/Latino Workers. Monthly Labor Review. 2013 (February 2013). Available online: https:/ / www.bls.gov/opub/mlr/2013/02/art2full.pdf (accessed on 24 March 2021).

88. Zhang, Z.; An, S.H. A comparative analysis of the safety awareness of Korean and Chinese construction workers. J. Korea Inst. Build. Constr. 2012, 12, 433-441. [CrossRef]

89. Choffray, J.M.; Johnson, P.E. Measuring perceived pre-purchase risk for a new industrial product. Ind. Mark. Manag. 1977, 8, 333-334. [CrossRef]

90. Ritchie, B.; Marshall, D. Business Risk Management; Chapman and Hall: London, UK, 1993.

91. Kim, J.T. The Study for Factors Influencing Construction Worker's Safety Consciousness. Master's Thesis, Soongsil University, Seoul, Korea, 2009.

92. Burke, M.J.; Sarpy, S.A.; Smith-Crowe, K.; Chan-Serafin, S.; Salvador, R.O.; Islam, G. Relative effectiveness of worker safety and health training methods. Am. J. Public Health 2006, 96, 315-324. [CrossRef]

93. Cameron, I.; Hare, B.; Duff, R.; Mc Nairney, F. Using pictures in training. In The Impact of Pictorial OSH Training on Migrant Worker Behaviour and Competence (Res. Rep. 11.2); Glasgow Caledonian University: Glasgow, UK, 2011.

94. Mushayi, T.; Deacon, C.; Smallwood, J. The effectiveness of health and safety training and its impact on construction workers' attitudes, and perceptions. In International Conference on Engineering, Project, and Product Management; Springer: Cham, Switzerland, 2017; pp. 235-244.

95. Haslam, R.A.; Hide, S.A.; Gibb, A.G.F.; Gyi, D.E.; Pavitt, T.; Atkinson, S.; Duff, A.R. Contributing factors in construction accidents. Appl. Erg. 2005, 36, 401-415. [CrossRef] [PubMed]

96. Williams, J.; Geller, E.S. Communication strategies for achieving a total safety culture: Employers need to overcome the perception that giving safety-related feedback creates interpersonal conflict. Occup. Hazards 2008, 70, 49-51.

97. Copper, D. The impact of management's commitment on employer behaviour: A field study. American Society of Safety Engineers, Middle East Chapter. In Proceedings of the 7th Professional Development Conference and Exhibition, Bahrain, 18-22 March 2006.

98. Teo, E.A.L.; Ling, F.Y.Y.; Chong, A.F.W. Framework for project managers to manage construction safety. Int. J. Proj. Manag. 2005, 23, 329-341. [CrossRef]

99. Gittleman, J.L.; Gardner, P.C.; Haile, E.; Sampson, J.M.; Cigularov, K.P.; Ermann, E.D.; Stafford, P.; Chen, P.Y. CityCenter and Cosmopolitan Construction Projects, Las Vegas, Nevada: Lessons learned from the use of multiple sources and mixed methods in a safety needs assessment. J Saf. Res. 2010, 41, 263-281. [CrossRef] [PubMed]

100. Ng, S.T.; Cheng, K.P.; Skitmore, R.M. A framework for evaluating the safety performance of construction contractors. Build. Environ. 2005, 40, 1347-1355.

101. Wu, C.; Li, N.; Fang, D. Leadership improvement and its impact on workplace safety in construction projects: A conceptual model and action research. Int. J. Proj. Manag. 2017, 35, 1495-1511. [CrossRef] 